\title{
The International Atmospheric Circulation Reconstructions over the Earth (ACRE) Initiative
}

\author{
by Rob Allan, Philip Brohan, Gilbert P. Compo, Roger Stone, \\ Juerg Luterbacher, and Stefan BrönNimanN
}

n 2006, climate applications scientists in Queensland, Australia, asked the lead author if a longer and more complete historical weather record could be created and fed directly into various crop, pasture, and production models. Existing dynamical reanalyses were steps toward such a product, but they spanned only the last six decades and had well-known shortcomings. To meet the needs of application scientists, new reanalyses would have to extend much further back in time while maintaining accuracy with limited observations. They would also need to be disseminated in a way that is easy to use directly and to downscale to small regions.

The above discussion arose just as researchers at the National Oceanic and Atmospheric Administration (NOAA), the University of Colorado, the National Center for Atmospheric Research (NCAR), and the European Centre for Medium-Range Weather Forecasts (ECMWF) were independently pursuing the controversial idea of reanalyses extending back to the nineteenth century using only surface weather observations. As these researchers demonstrated that such

AfFiliations: Allan ANd Brohan-Met Office Hadley Centre, Exeter, United Kingdom; CoMPO-University of Colorado, CIRES, Climate Diagnostics Center, and NOAA Earth System Research Laboratory, Physical Sciences Division, Boulder, Colorado; STONE-Australian Centre for Sustainable Catchments, University of Southern Queensland, Toowoomba, Australia; LUTERBACHERClimate Dynamics and Climate Change, Department of Geography, Justus-Liebig University of Giessen, Germany; BRÖNNIMANN-Oeschger Centre for Climate Change Research, University of Bern, Switzerland

CORRESPONDING AUTHOR: Rob Allan, International ACRE Project Manager, Met Office Hadley Centre, FitzRoy Road, Exeter, EXI 3PB, United Kingdom

E-mail: rob.allan@metoffice.gov.uk

DOI:10.II75/20IIBAMS32I8.I

(C)20II American Meteorological Society

\section{sparse-input reanalyses were feasible, an international reanalysis workshop considered the issues of overall improvements for climate applications. To implement these ideas would require new work on data assimila- tion, extensive efforts to recover worldwide historical weather observations, and new ways of distributing and utilizing large gridded reanalyses. The Atmospher- ic Circulation Reconstructions over the Earth (ACRE) Initiative was established with the goal of facilitating such research by coordinating existing national and international projects, and also encouraging and un- dertaking the additional work needed to produce and use "reanalyses for climate applications." \\ ACRE is led by seven core partners who provide funding and undertake key parts of the needed efforts: the Queensland State Government and the University of Southern Queensland in Australia; the UK Met Office (UKMO) Hadley Centre; the NOAA Earth System Research Laboratory (ESRL) and the Climate Diagnostics Center (CDC) of the Cooperative Institute for Research in Environmental Sciences (CIRES) at the University of Colorado at Boulder; NOAA's National Climatic Data Center (NCDC); and the universities of Giessen in Germany and Bern in Switzerland. This core team works with more than 35 projects, institu- tions, and organizations around the globe (Fig. 1) in an international context coordinated with the Global Earth Observations System of Systems, the Global Climate Observing System (GCOS), the World Me- teorological Organization (WMO), the World Climate Research Programme (WCRP), and the Intergovern- mental Ocean Commission (IOC).}

ACRE-FACILITATED RECOVERY, IMAGING, AND DIGITIZATION OF HISTORICAL GLOBAL SURFACE WEATHER OBSERVATIONS. ACRE works closely with the international surface weather and climate observations community-particularly the International Surface Pressure Databank (ISPD; http://dss.ucar.edu 


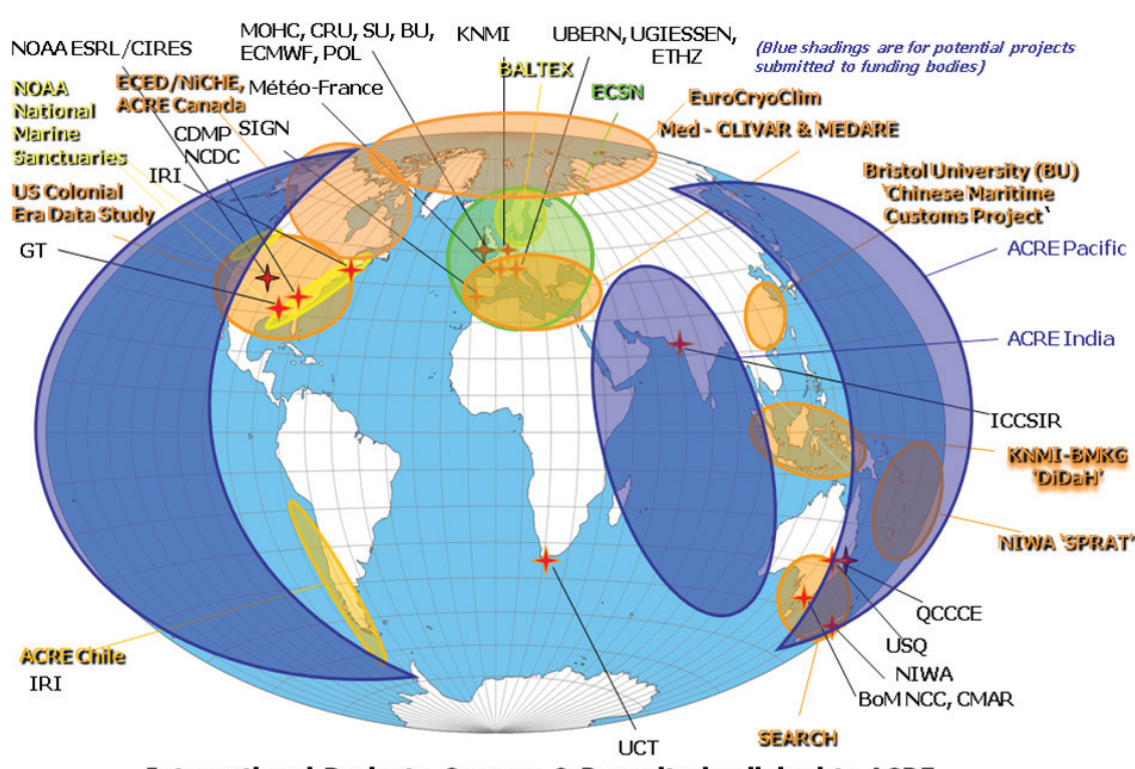

International Projects, Sources \& Repositories linked to ACRE

IEDRO ICOADS ISPD WMO DARE RECLAIM GLOBE GLOSS ETCCDI VACS ICHM Galaxy Zoo CoRRaL EUFP7: EURO4M EUFP7:ERA-CLIM NERC: AUSTRAL Reanalysis.org

FIG. I. The full global range of collaborations, linkages, and projects involved in ACRE to date. Acronyms not defined in the text in Figs. $I$ and 2 are defined and detailed at http://sites.google.com/a/met-acre.org/acre/links.

worked closely with ACRE include the U.K. Colonial Registers and Royal Navy Logbooks project ( $w$ ww .corral.org.uk).

As well as providing a framework for large projects, ACRE undertakes smallerscale digitization of material from secondary sources such as published books, journals, ship logbooks, and reports of marine and terrestrial weather data from expeditions, travels, circumnavigations, and ships of exploration. This material provided valuable polar observations for the 20th Century Reanalysis Project (20CR). Other efforts include creating inventories of undigitized data holdings, such as 6,000 U.K. hydrographic and survey vessel remarks books at the U.K.

/datasets/ds 132.0), the International Comprehensive Ocean-Atmosphere Data Set (ICOADS; http://icoads noaa.gov), the international RECLAIM (RECovery of Logbooks And International Marine data project; http://icoads.noaa.gov/reclaim), the International Environmental Data Rescue Organisation (IEDRO; www.iedro.org), and NOAA's NCDC Climate Database Modernization Program (CDMP; www.ncdc .noaa.gov/oa/climate/cdmp/cdmp.html). Together with academics and archives, they are working to expand the recovery, imaging, and digitization of historical instrumental weather observations. ACRE provides an umbrella under which these often diverse-and regional-activities can be focused and coordinated internationally.

Specific projects that ACRE has facilitated over the last four years include major data recovery projects, such as 900 logbooks from ships of the English East India Company (EEIC) (1780s-1830s) sailing the North and South Atlantic Oceans, the Indian Ocean, and the South China Sea (imaged by the British Library [BL] and digitized by CDMP), and $~ 7,000$ Royal Navy logbooks from the extended period encompassing World War I (1914-23, imaged by the U.K. National Archives [TNA] and digitized under www.oldweather.org). Other projects that have
Hydrographic Office (spanning 1834-1909), and Chinese and South China Sea weather observations made by the Chinese Maritime Customs (with Bristol University; www.bristol.ac.uk/history/customs).

Finally, many regional activities, foci, and linked projects comprise the associated parts of the initiative (Fig. 1). Some examples are ACRE Chile, which aims to digitize nineteenth- and twentieth-century weather observations in Chilean archives (part of the ECMWF-led European Commission [EC] Seventh Framework Programme Cooperation [FP7] project on European Reanalysis of Global Climate Observations [ERA-CLIM]); ACRE Pacific, with recent funding from the French Pacific Fund; ACRE India, which is developing as part of a BL-India initiative; and the South Eastern Australian Recent Climate History project (www.climatehistory.com .au), which is assembling pre-twentieth-century data suitable for temperature, rainfall, and atmospheric pressure reconstructions. Recently, ACRE also played an important role in developing the $w w w$ surfacetemperatures.org project.

Figure 2 shows how the recovered and digitized weather observations flow through the international surface weather observational framework and infrastructure and into international repositories. 
ACRE-FACILITATED REANALYSES. For most users, raw observational data, with limited and variable spatial coverage, have little utility. Significant value can be added by assimilating observations into a dynamical reanalysis: a global, gridded reconstruction of the weather generated by objectively combining numerical weather forecasts in hindcast mode with observations (www.reanalyses.org). Prior to ACRE, the longest reanalyses only extended back to 1948 . Even today, most cover only the last few decades. A much longer reanalysis dataset is desirable to provide users with the perspective needed to investigate, understand, and adapt to climate variability and change. ACRE and its U.S. partners have already begun to achieve this, with the ISPD and enhanced ICOADS databases providing the observations allowing 20CR to span the years 1871-2008.

At a 2010 reanalysis workshop at NASA's Global Modelling and Assimilation Office, ACRE was recognized as being an important data coordinator and provider of surface data for all future reanalyses in collaboration with working groups of GCOS and WCRP. This role has been further strengthened by ACRE's involvement in two new EC FP7 projects: the Royal Netherlands Meteorological Institute (KNMI)-led European Reanalysis and Observations for Monitoring (EURO4M), and the ECMWF-led ERA-CLIM. Additional reanalyses are also envisioned by ACRE's partners at NOAA/ESRL and

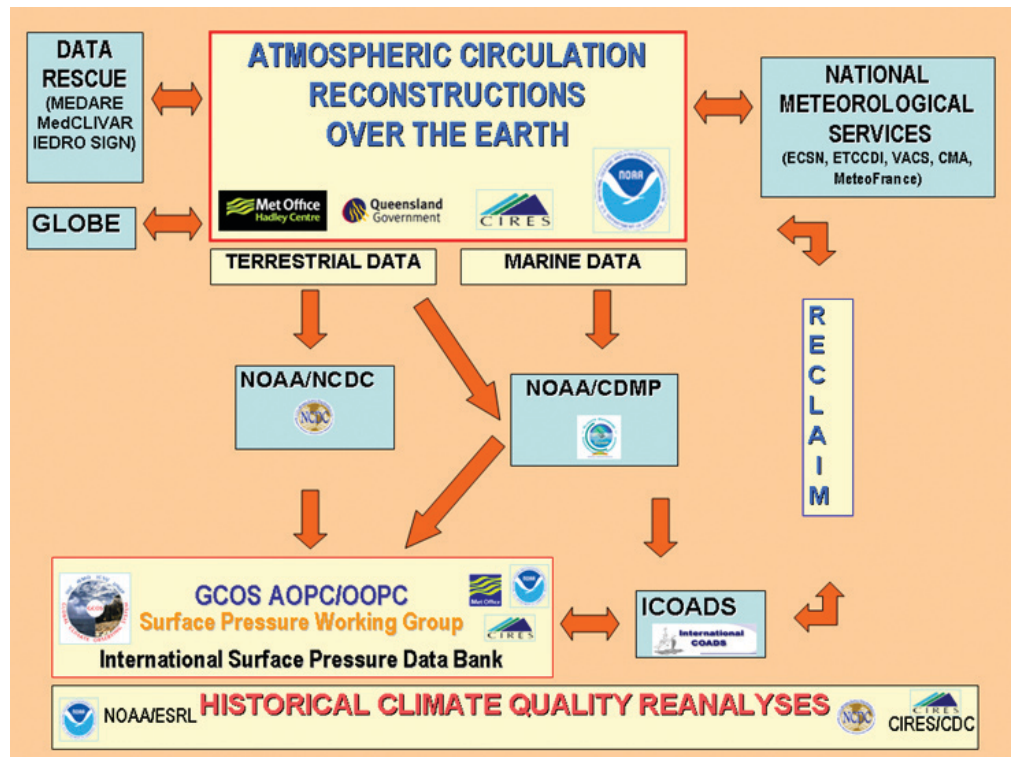

Fig. 2. ACRE data flow within the international surface terrestrial and marine infrastructure.
CIRES/CDC, covering even longer periods: a Sparse Input Reanalysis for Climate Applications (SIRCA) 1850-2014, and eventually extending back to 1800 at 6-hourly resolution.

The impact that ACRE's data-recovery activities are expected to have on the amount of global historical surface weather observations available for future reanalyses can be seen in Fig. 3 .

\section{ACRE FACILITATES USING OBSERVA-} TIONS AND REANALYSES. The envisioned reanalyses will produce reconstructions of global historical weather conditions that can serve the full range of international users. To make them as user-friendly, tailored, widely available, and interactive as possible, ACRE is embracing the development of technologies in massive-scale data handling and web-based, stateof-the-art, high-resolution visualizations.

The first ACRE-facilitated reanalysis product, the 20CR Version 2 dataset, has global four-times-daily atmospheric and surface fields spanning 1871-2008. Data access and plotting tools are described at www .esrl.noaa.gov/psd/data/20thC_Rean.

The 20CR generates global gridded wind, temperature, pressure, humidity, and other variables at $2^{\circ}$ latitude by $2^{\circ}$ longitude horizontal resolution and 28 vertical levels with an ensemble of 56 analyses for each 6-hourly time step. The 20CR also generates quality control information and other metadata about the ISPD observations. These so-called "feedback" records are included as part of the ISPD, which is freely available to users courtesy of NCAR (http://dss .ucar.edu/datasets/ds|32.0).

Existing technologies struggle to handle the full 20CR output in an efficient manner. ACRE envisions the historical surface observations, data images, and metadata, plus the entire 20CR output to be made freely accessible via twenty-first-century technology, such as that of the evolving UKMO-UK Technology Strategy Board-IBM Open Platform. If successful, this Open Platform and other technologies will allow policy makers and scientists alike to use 20CR and other reanalyses to address climate variability and change issues in ways and over time spans not previously possible. 


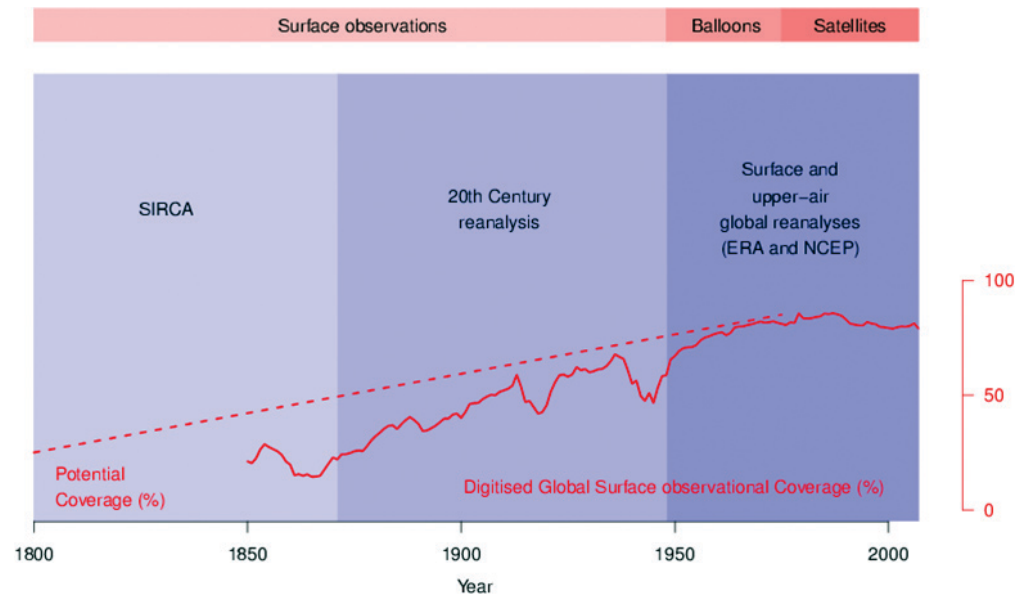

FIG. 3. Potential impact of ACRE data activities on surface observations available for historical reanalyses. Solid red line is a schematic of the percentage of global surface observations already digitized; the dashed red line shows the potential improvement in global surface observations digitized as a result of ACRE. The blocks shaded blue through time show the range of ACRE-facilitated historical weather reanalyses in the context of contemporary international NCEPNCAR and ECMWF reanalyses.

As user interaction and engagement are fundamental components of ACRE, strenuous efforts are underway to bring together climate researchers, the diverse climate-applications community, educators, students, and the general public. ACRE is engaging with wider cross- and interdisciplinary initiatives such as the international student GLOBE Program and its Student Climate Research Campaign (SCRC) for 2011-13 (www .globe.gov/scrc), and the OldWeather.org (www .oldweather.org/) and Data.Rescue@Home (www data-rescue-at-home.org) citizen science projects.

As these data and reanalyses products and their potential uses become more widely known, their value will increase. Early projects are addressing extremes (such as storm intensity), climate modes, and reanalysis-based approaches to agricultural resilience. Wider applications will come from their expanded use in conjunction with new high-resolution reanalyses for Europe EURO4M and the longer global reanalyses of ERA-CLIM.

The historical record of climate variability is of interest outside the weather and climate community. A series of recent collaborations between ACRE and social sciences and humanities partners have led to broader applications and outreach for reanalysis products (e.g., the Shipping Archives and Integrated Logbooks of Ships [SAILS; http://sailsproject.cerch.kcl .ac.uk]) and Historic Weather (http:// historicweather.cerch.kcl.ac.uk /node/I2) projects.

\section{ACRE MEETINGS, WORK- SHOPS, AND WEB SITES. ACRE} achieves its goals by encouraging communication and joint projects between observational recovery experts, reanalysis producers, and data users. Three examples are web sites such as ACRE's homepage (www .met-acre.org), the Reanalysis Intercomparison and Observations site (www.reanalyses.org), and an e-mail discussion list. Additionally, ACRE has held three full international workshops covering all aspects of the initiative and two specific meetings under ACRE Working Group 1: Data Rescue. All of the presentations made at these workshops and meetings can be downloaded from www.met-acre .org/meetings-and-workshops-I. The recent 3rd ACRE Workshop in Baltimore highlighted the broad scope of the ACRE community, with presentations ranging from observation recovery in the Arctic to weather extremes and climate change to heritage architecture monitoring. The 4th ACRE Workshop was held at KNMI in De Bilt, Netherlands, in late September 2011.

FUTURE ACTIVITIES. ACRE has shown what can be done to develop and fuse together global observations and reanalyses with user needs, activities, and engagements. Going forward, this initiative is implementing major elements of the strategic plans of the international scientific community for climate information as it generates outputs and outreach that satisfy and engage users worldwide.

The initiative has developed a viable international data recovery, imaging, and digitization program that works with the existing infrastructure and combines a mixture of activities covering the full spectrum from small "cottage"- to extensive "industrial"-scale projects. This work has also initiated engagements with researchers and institutions in the social sciences and humanities, and captured masses of contextual material that such disciplines need but can rarely access in such quantities.

ACRE is a response to user needs. Through its core linkages between observations, reanalyses, and the 
tailoring, shaping, and downscaling of that material in alignment with user requirements, the initiative is filling a vital role in making climate-science products freely available and their generation transparent to all users. Through its efforts to develop state-of-the-art visualization technology, the initiative is building the infrastructure to deliver its output and outreach globally. In 2010, ACRE and its activities were ratified by the WMO Commission for Climatology, highlighted in the GCOS Implementation Plan (2010 Update), and endorsed by WCRP and by the Expert Team on Marine Climatology of the Joint WMO-IOC Technical Commission on Oceanography and Marine Meteorology.

In any of its components, ACRE welcomes further engagement with the international community.

ACKNOWLEDGMENTS. The initiative owes much to the huge range of individual colleagues, institutions, organizations, and projects around the world who have not only eagerly supported it and the core partners but have made it their own. The 20CR used the resources of NERSC and the Oak Ridge Leadership Computing Facility at Oak Ridge National Laboratory, which are supported by the Office of Science of the U.S. Department of Energy under Contract No. DE-AC02-05CH11231 and Contract No. DE-AC0500OR22725 respectively. The 20CR is supported by the U.S. Department of Energy, Office of Science Innovative and Novel Computational Impact on Theory and Experiment program, the Office of Biological and Environmental Research, and the NOAA Climate Program Office.

\section{FOR FURTHER READING}

Allan, R. J., G. P. Compo, and J. Carton, 2011: Recovery of global surface weather observations for historical reanalyses and international users. Eos, 92, 154, doi:10.1029/2011EO180008.

Anderson, J. L., B. Wyman, S. Zhang, and T. Hoar, 2005: Assimilation of surface pressure observations using an ensemble filter in an idealized global atmospheric prediction system. J. Atmos. Sci., 62, 2925-2938.

Bengtsson, L., and Coauthors, 2007: The need for a dynamical climate reanalysis. Bull. Amer. Meteor. Soc., 88, 495-501, doi:10.1175/BAMS-88-4-495.

Compo, G. P., J. S. Whitaker, and P. D. Sardeshmukh, 2006: Feasibility of a 100-year reanalysis using only surface pressure data. Bull. Amer. Met. Soc., 87, 175-190.

— , and Coauthors, 2011: The Twentieth Century Reanalysis Project. Quart. J. Roy. Meteor. Soc., 137, 1-28. doi:10.1002/qj.776.

GCOS, 2010: Implementation plan for the global observing system for climate in support of the UNFCCC (2010 Update). WMO/TD-No. 1523. [Available online at www.wmo.int/pages/prog/gcos/Publications/ gcos-138.pdf.]

Whitaker, J. S., G. P. Compo, X. Wei, and T. M. Hamill, 2004: Reanalysis without radiosondes using ensemble data assimilation. Mon. Wea. Rev., 132, 1190-1200. 